\title{
Unruptured non-coronary sinus of Valsalva aneurysm - case report
}

\section{Mijo Meter*, OZora Sušilović Grabovac, \\ -Antonia Melada, DJosip Katić, Olvona Mustapić, DViktoria Lišnić, DDarija Baković Kramarić}

University of Split School of Medicine, University Hospital Centre Split, Split, Croatia
RECEIVED:

February 28, 2019

ACCEPTED:

March 24, 2019

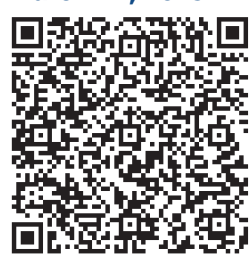

KEYWORDS: sinus of Valsalva aneurysm, echocardiography.

CITATION: Cardiol Croat. 2019;14(3-4):51. | https://doi.org/10.15836/ccar2019.51

*ADDRESS FOR CORRESPONDENCE: Mijo Meter, Klinički bolnički centar Split, Spinčićeva 1, HR-21000 Split, Croatia. / Phone: +385-98-9752-946 / Email: mijometer05@gmail.com

ORCID: Mijo Meter, https://orcid.org/0000-0003-4674-426X • Zora Sušilović Grabovac, https://orcid.org/0000-0001-9999-7557 Antonia Melada, https://orcid.org/0000-0003-4223-2582 • Josip Katić, https://orcid.org/0000-0002-4991-1919 Ivona Mustapić, https://orcid.org/0000-0002-1534-3642 • Viktoria Lišnić, https://orcid.org/0000-0001-7598-6749 Darija Baković Kramarić, https://orcid.org/0000-0001-6751-5242

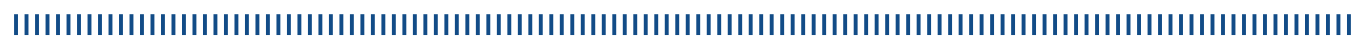

Introduction: Sinus of Valsalva aneurysm (SVA) is an abnormal dilatation of the aortic root located between the aortic valve annulus and the sinotubular junction. The estimated rate of SVA is approximately $0.09 \%$ of the general population and involve up to $3.5 \%$ of all congenital heart defects ${ }^{1}$. Aneurysm predominantly originates from the right coronary sinus and may rupture up to $35 \%$ of the time commonly to the right cardiac chambers ${ }^{2}$. We present an unusual case of a patient with SVA originating from the non-coronary sinus.

Case report: 63-old-year male with no history of prior cardiovascular disease was presented to department with shortness of breath and chest pain. Physical examination showed blood pressure of $140 / 80 \mathrm{mmHg}$, respiratory rate of 18/min and heart rate of 84 beats/min. Electrocardiogram revealed complete right bundle-branch block. A routine transthoracic echocardiography showed the enlargement of the left ventricle with large aneurysm originating from non-coronary sinus measuring $3.6 \times 4 \mathrm{~cm}$. Echocardiography also revealed a trileaflet aortic valve with moderate aortic regurgitation and normal systolic function of the left ventricle. TEE demonstrated a non-coronary SAV protruding into the left atrium cavity with no signs of rupture. Selective angiography showed normal epicardial coronary arteries, and SAV with dilatation of ascending aorta measuring up to $40 \mathrm{~mm}$. Moderate aortic insufficiency was also detected. The patient was referred to the cardiothoracic surgery ward for further operative treatment.

Conclusion: Although rare, SAV can be a cause of sudden death. Therefore, a combination of transthoracic echocardiography with other imaging techniques, such as TEE, 3D echocardiography, CT angiography and aortic angiography is recommended to obtain comprehensive information and to improve diagnostic accuracy ${ }^{3}$.

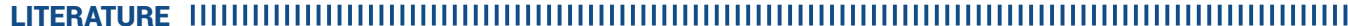

1. Bricker AO, Avutu B, Mohammed TL, Williamson EE, Syed IS, Julsrud PR, et al. Valsalva sinus aneurysms: findings at CT and MR imaging. Radiographics. 2010 Jan;30(1):99-110. https://doi.org/10.1148/rg.301095719

2. Fritz AV, Boles KS, Martin AK. Echocardiographic evaluation of aorta to right atrial fistula secondary to ruptured sinus of valsalva aneurysm. Ann Card Anaesth. 2018 Jul-Sep;21(3):313-314. https://doi.org/10.4103/aca.ACA_229_17

3. Yang Y, Zhang L, Wang X, Lü Q, He L, Wang J, et al. Echocardiographic diagnosis of rare pathological patterns of sinus of Valsalva aneurysm. PLoS One. 2017 Mar 14;12(3):e0173122. https://doi.org/10.1371/journal.pone.0173122 